The Journal of Animal \& Plant Sciences, 30(6): 2020, Page: 1604-1611

ISSN (print): 1018-7081; ISSN (online): 2309-8694

\title{
FIRST RECORD OF TOMATO LEAFMINER, TUTA ABSOLUTA (MEYRICK 1917) (LEPIDOPTERA: GELECHIIDAE) FROM SOUTHERN PART OF PUNJAB, PAKISTAN
}

\author{
M. Ishtiaq ${ }^{1}$, M. Sadique ${ }^{1 *}$, N. Faried ${ }^{2}$, U. Naeem-Ullah ${ }^{1}$ and M. A. Hamza ${ }^{1}$ \\ ${ }^{1}$ Department of Entomology, Institute of Plant Protection, MNS University of Agriculture Multan, Punjab (Pakistan) \\ ${ }^{2}$ Department of Horticulture, MNS University of Agriculture Multan, Punjab (Pakistan) \\ Corresponding author's email: saddique.rana@gmail.com
}

\begin{abstract}
Tomato leafminer, Tuta absoluta is an indigenous insect pest of solanaceous crops in South America, which is now an important quarantine insect pest in many other parts of the world. Geographical range of T. absoluta is rapidly increasing. It has been spreading in Asian countries since first reported from Turkey in 2009, Azarbaijan province in North Western Iran in 2010 and in 2014 it has reached India. Its damage is severe on tomatoes and possible threat to food production hence an emerging problem to food security. Tuta absoluta was not reported earlier in Pakistan. A high attack of Tuta absoluta in 2017-2018 in Multan on tomato crop was observed. Samples were recovered from tomatoes grown under plastic tunnels. Detection was carried out by incubated infested tomato leaves and fruits till adult eclosion in the mesh cages. Larvae were observed under microscope. Leaves and fruit damage symptoms were compared with available data. Adults were identified morphologically. Genitalia of adults proved that insect pest was tomato leafminer, Tuta absoluta. Furthermore, it was confirmed through sex pheromone traps where moths of Tuta absoluta were caught from same location from where samples were taken. Hence, it is confirmed first report of T. absoluta in Pakistan. Further studies are needed to confirm the occurrence of this emerging insect pest on alternative host plants in different areas of Pakistan. It's an alert for quarantine department to take strict measures for its entry points through trade before it emerges as threatening insect pest in Pakistan to tomato industry.
\end{abstract}

Key words: Tomato leafminer, Tuta absoluta, Invasive pest, First report

https://doi.org/10.36899/JAPS.2020.6.0181

Published online August 03,2020

\section{INTRODUCTION}

The insect pest invasions have been rapidly increasing due to increasing global trade around the world (Pimentel et al. 2001). Furthermore, in the current scenario of climate change, abundance, trans-border distribution and invasions of pest species are increasing globally (Hill et al. 2016). In the past decades from developing countries the vegetable export has massively increased and horticultural exports from these developing countries have been reported to contribute in upgrading of livelihoods and food security (Van den Broeck and Maertens, 2016). Tomato, Solanum lycopersicum L. (Solanales: Solanaceae) is categorized as delicious and nutritious food and valuable crop (Tumuhaise et al. 2016). However, its production in terms of quality and quantity is at risk due to multiple factors especially by insect pests.

T. absoluta is a key insect pest of tomato which also known as tomato pinworm of Southern America (Brevault et al. 2014). If it is left uncontrolled, it is a destructive pest of tomato fruit and plants causing yield losses between 80 to $100 \%$ (Desneux et al. 2010). Its feeding has also been observed on a wide host range of solanaceae family i.e. potato, garden bean, tobacco, eggplant pepper and solanaceous wild weeds (Solanum puberulum, S. nigrum, S. elaeagnifolium, Nicotiana glauca, Datura stramonium and D. ferox) (Ferracini et al. 2012). It has been reported as widespread in different continents emerging from South America to Africa, Europe and Asian countries. Tuta absoluta was first reported in Argentina in 1964 (Bahamondes and Mallea, 1969), Spain in 2006 (Urbaneja et al. 2007), BosniaHercegovina in 2010 (Duric et al. 2012), Sudan and Iran in 2010 (Mohamed et al. 2012; Baniameri and Cheraghian, 2012; Cheraghian and Emamzadeh, 2013) and Tanzania, Karnataka and Maharashtra (India) in 2014 (Sridhar et al. 2014; Shashank et al. 2015; EPPO, 2018). In African countries this pest attack was reported from South Africa, Uganda and Zambia in 2016 (Tumuhaise et al. 2016; EPPO, 2018). This insect pest has been observed in Madhya Pradesh, India in 2017 (Swathi et al. 2017) and Lesotho in 2018 (EPPO, 2018). Now, this insect pest is spreading to all tomato growing areas of the world.

Import of tomato from India and Iran to cover the increasing demands could be possible source of entry of tomato leaf miner in Pakistan which already reported in India in 2014 (Swathi et al. 2017; Shashank et al. 2015 and Sridhar et al. 2014). Packing material inflowing from infested countries is one of the sources behind wide spread of this insect pest (Potting et al. 2013). Short 
distance spread of this pest could possible by flight as this pest can actively fly several kilometers, while long distance dispersion could be by human assisted means (Ramos et al. 2013). Lack of inter quarantine rules and movement of tomato from one place to another within country, could help spread this invasive tomato insect pest to whole country in future within short time. $T$. absoluta could also move to other parts of Pakistan across the border trade among Pakistan, Iran and India.

Presence confirmation in India and Middle East makes Pakistan, Afghanistan, China and Nepal as risk areas (Sensitizing workshop on Tuta absoluta in Nepal, 2015). This destructive pest is found in many tomato growing areas. This pest has several generations in a year, so the outbreaks of this pest in Pakistan and Iran is possible in future years owing to climatic conditions are ideal for this insect pest survival (Anonymous, 2013). It has been warned by different authors for its potential invasion in Pakistan, due to its presence in neighboring countries. But, it is not being reported in Pakistan to date. This is the first record of presence of T. absoluta in Pakistan.

\section{MATERIALS AND METHODS}

Samples of leafminers were collected from tomato crop grown under plastic tunnels, at Multan (Southern Punjab) Pakistan. Two sites were sampled in the radius of 5 Kilometers. Damage symptoms were very similar to Tuta absoluta. After detection, a physical appraisal of crop damage was conducted for pest existence. Infested samples of tomato fruit were collected and placed in climate growth chambers for incubation in insect cages until adult emergence. Emerged adult moths were collected and examined for confirmation.

Moths were put in the killing jars with chloroform absorbed cotton swab. T. absoluta can be identified morphologically using male genital features like valvae and gnathos (Hayden et al. 2013). Males contained broad, horseshoe-shaped gnathos and a digitate valva, with a medial hump and constriction (Hejazi et al. 2016). Identification was done by following methods used by Roditakis et al. 2010; Sridhar et al. 2014 and Shashank et al. 2015.

Damage symptoms on tomato: Infested tomato leaves and fruits were collected from plastic tunnels and examined via visual cues and larvae were examined under microscope in the laboratory. Photographs of infested leaves were taken with the help of illuminated bench stereomicroscope, Euromex stereoBlue (model S/N - EU 1870851), fitted with a microscope-mounted 5.0-MP digital camera (CMEX-5) (Holland), connected to computer.

Morphological identification: Morphological characters of adults of leaf miners were examined under stereomicroscope connected to computer. Pictures of different life stages egg, larva, pupa and adult were taken.

Trapping through Sex Pheromone Traps:

A species specific sex pheromone lures baited with chemical (3E, 8Z, 11Z) -3,8,11-tetradecatrien-1yl acetate or TDTA (90\%) and (3E, 8Z) $-3,8$ - tetradecadien-lyl acetate or TDDA

(10\%) that attract males of Tuta absoluta were imported from China manufactured by Beijing Zhongjie Sifang Biotechnology Co., Ltd. China.

These lures were placed in delta traps containing sticky sheet at its base and hanged in tomato crop grown under plastic tunnels during winter months i.e., November to February. Tunnels were removed in MarchApril due to rise in temperature, a common practice of growing tomato crops in winter in the Punjab. Traps were hanged at two different sites with separate tunnels within 5 Square $\mathrm{Km}$ in Multan (Pakistan). Moths captured in the trap were observed for confirmation of leaf miner species.

\section{RESULTS}

Tomato plants were infested with leaf miners showed characteristic symptoms of leaf and fruit damage. The shoots showed the signs of wilting, die back, and dead hearts. Wilting, chlorosis, large necrotic areas and lesions of different sizes were seen on leaves (Fig. 1a, b, c). The infested parts of plants were largely visible with frass. Irregular shapes and small holes are made by the tomato fruit borer when the fruit is not old (Fig. 2). In the later stages of fruit, the fruit shows the signs of decomposition followed by secondary infections.

Main identification characters of Tuta absoluta (Meyrick 1917): Head vertex covered with appressed scales, flattened against the head. The mouth area (labial palps) were scale like and head with a distinguishingly forward projecting, upward curved shape with long pointed apical segment. Male reproductive part (genitalia) was also confirmed by previously reported scientists work (Hayden et al. 2013; Visser et al. 2017). The hood shaped uncus was observed broad at the apex margin which attached to tegument at base, broadened with an ovate gnathos. The aedeagus was broader, basal prominent caecum, digitate valva within inner margin arched shape, and valva covered with less dense hairs (setae). The specimen has well developed vinculum with broad and elongated saccus. Antennae of Tuta absoluta long, thin, and bicolor banded with gray and dark brown (Fig. 4). The larvae of T. absoluta can be differentiated by the presence of a dark distinct prothoracic shield on larvae just behind the head (Fig. 5). 
Sex Pheromone: Moth trap catches found in sex pheromones baited with male attracted chemical placed in delta traps provided evidence (Fig. 3). Based on plant damage symptoms, morphological characters, and moth trap catches, it is concluded that it is the first record of Tuta absoluta (Meyrick) (Lepidoptera: Gelechiidae) from Punjab (Pakistan).

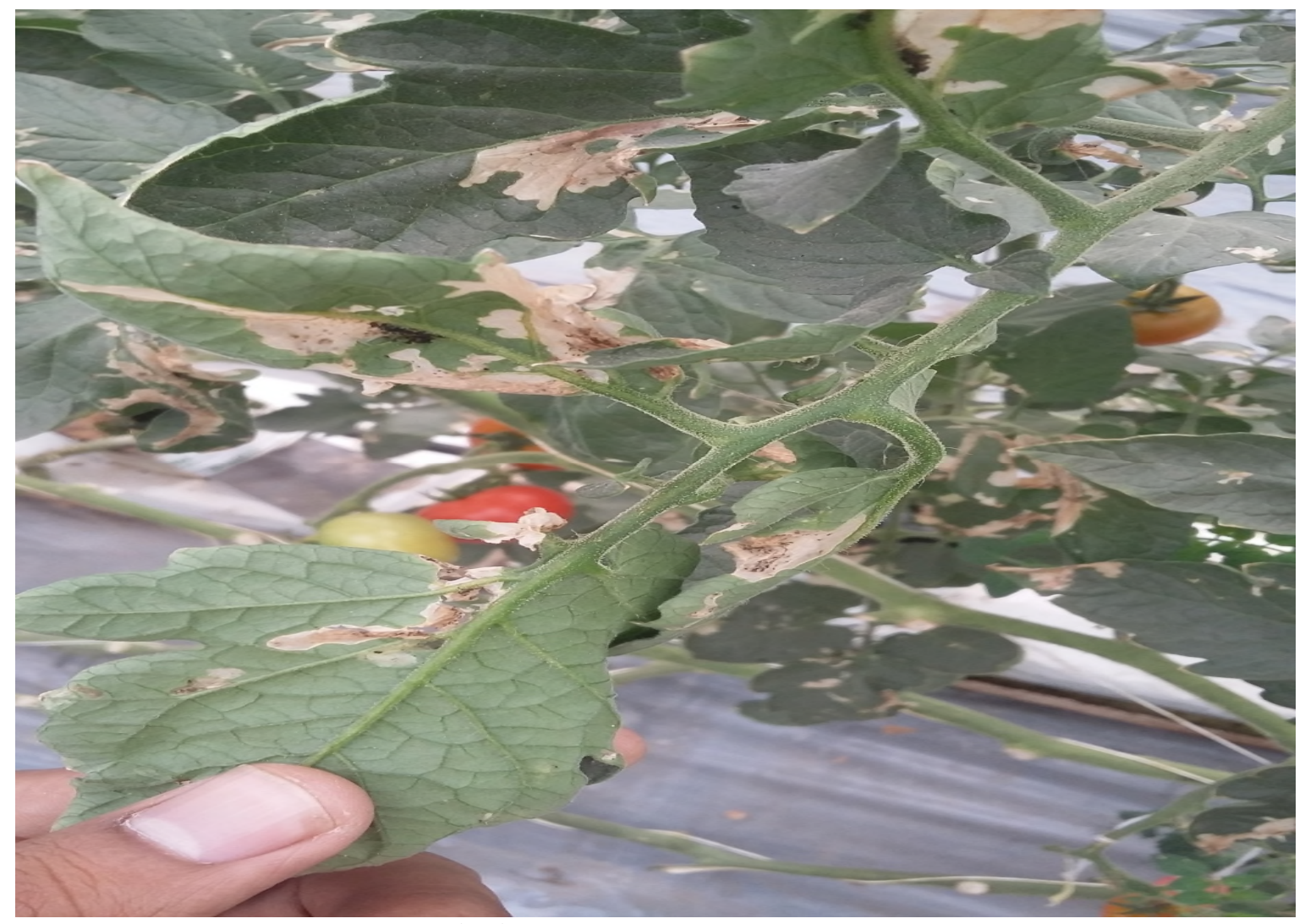

Fig. 1a Leaves damaged by larvae of T. absoluta

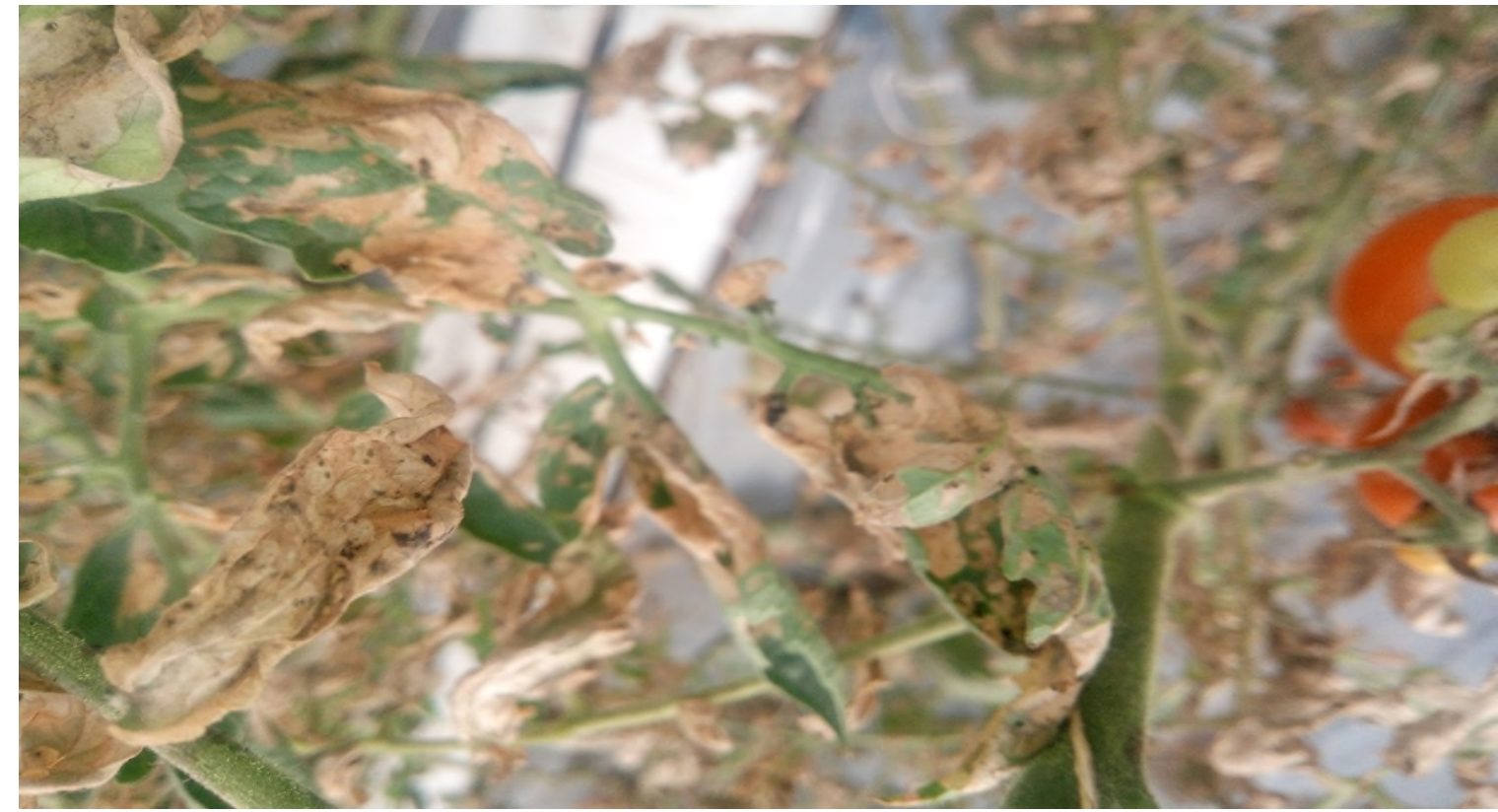

Fig. 1b Leaves damaged by larvae of $T$. absoluta 


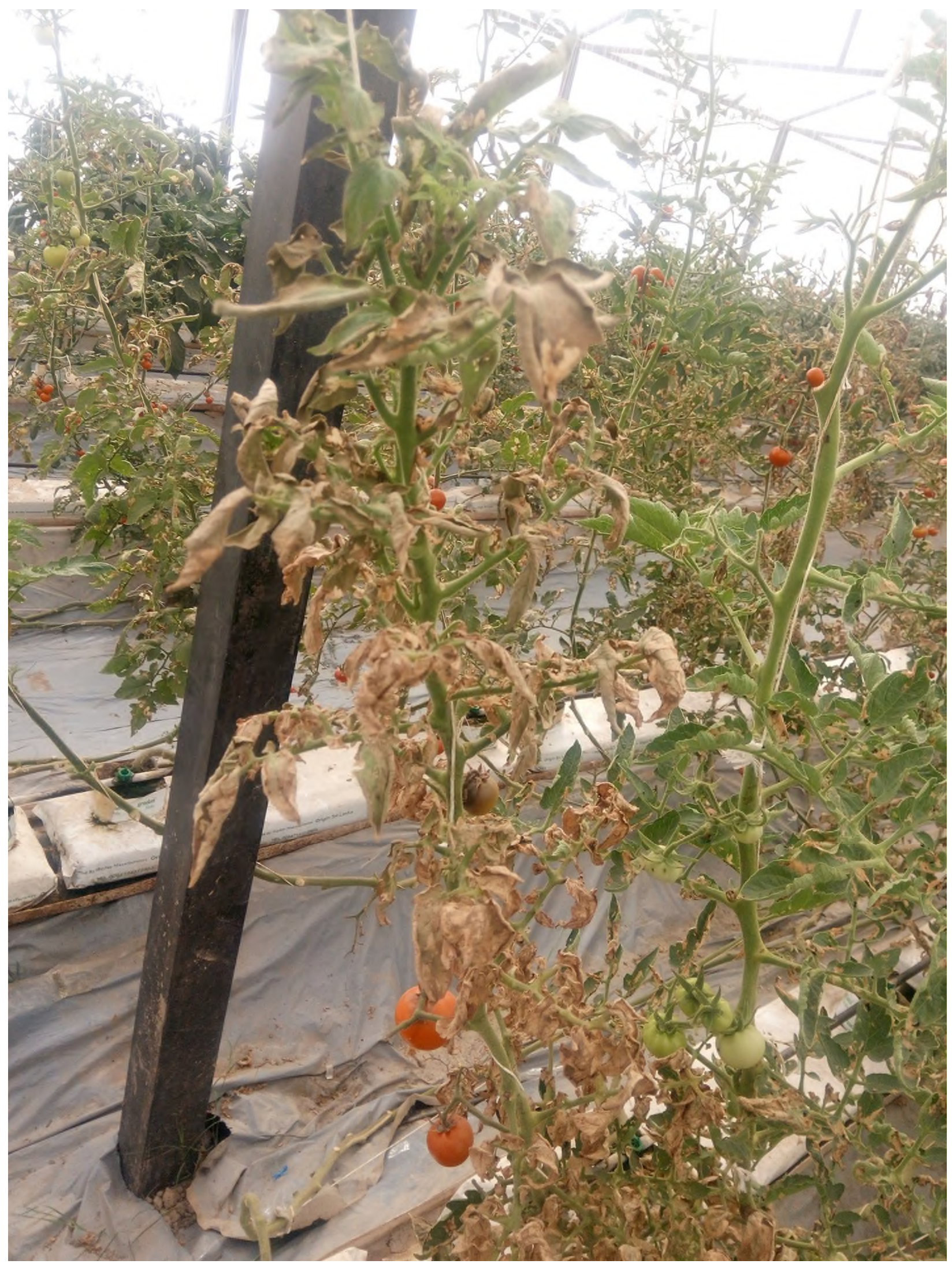

Fig. 1c. Damaged plant 


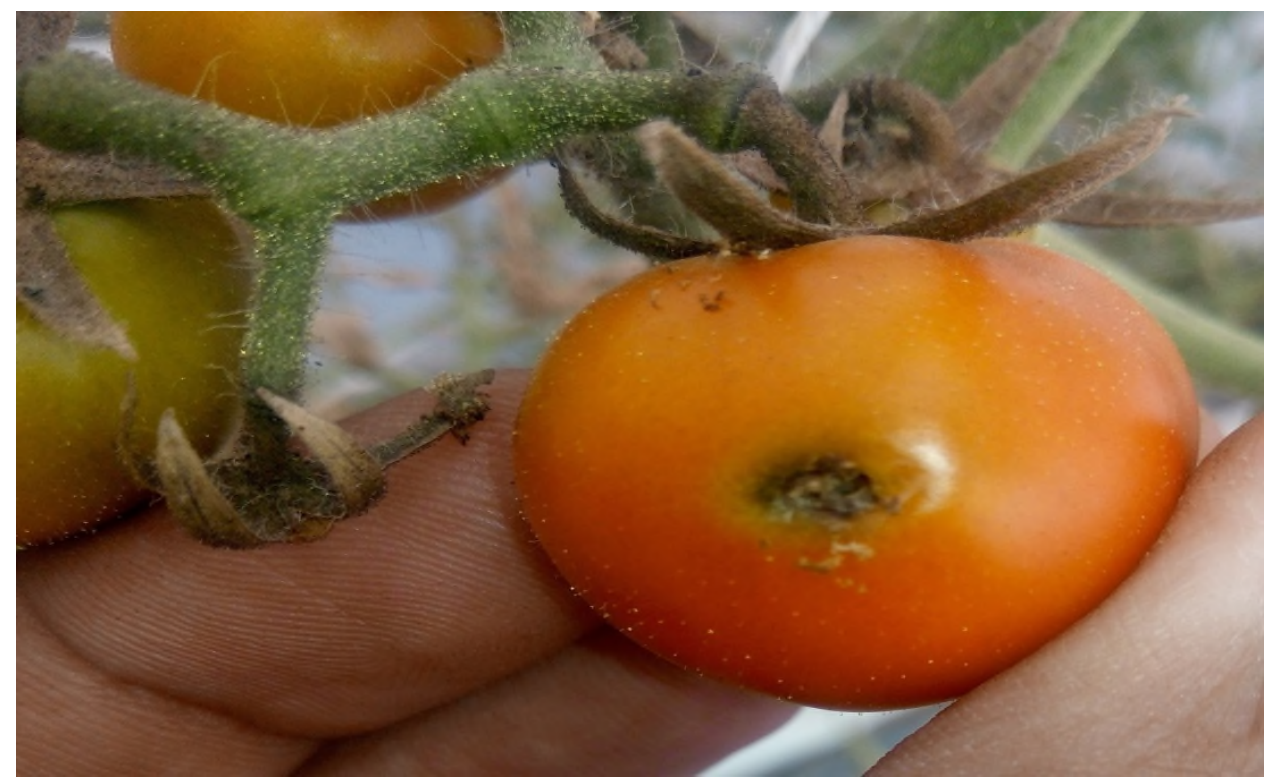

Fig. 2. Larval damage on fruit

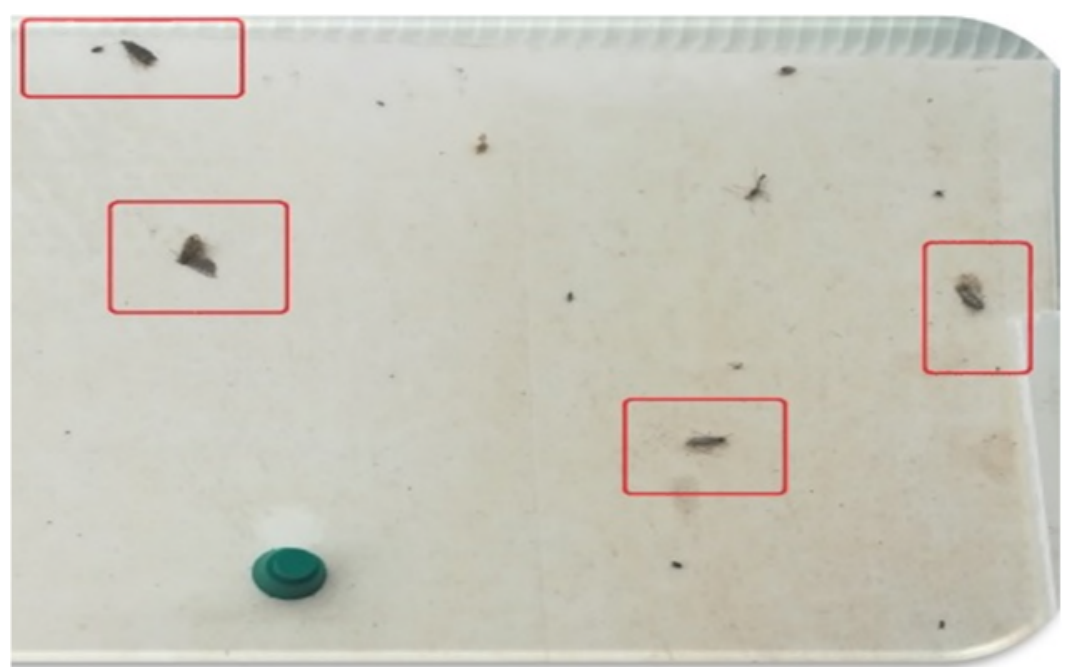

Fig. 3. Moths of $T$. absoluta (encircled) on sex pheromone trap

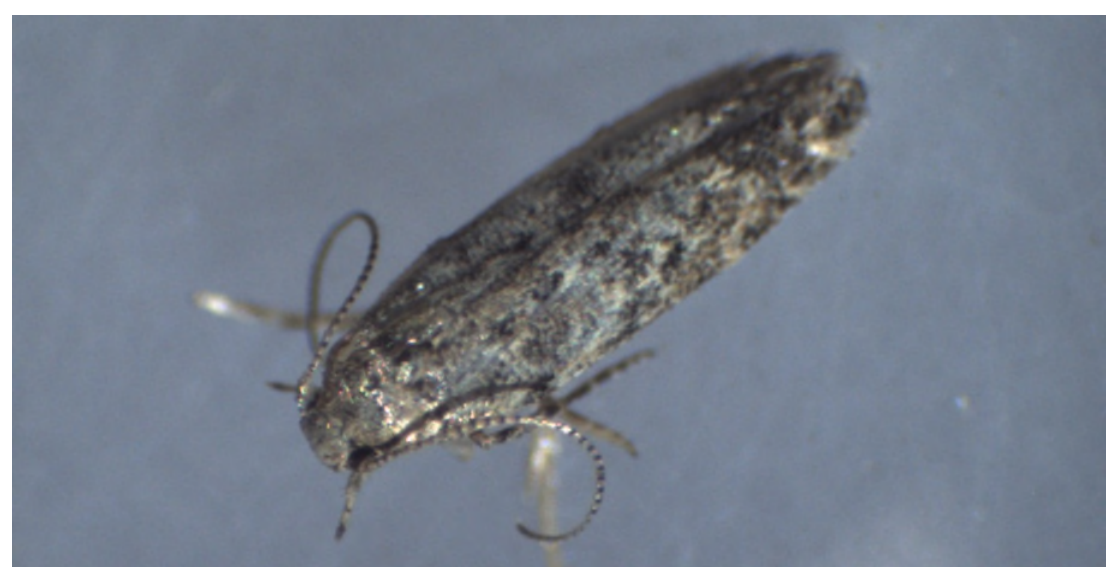

Fig. 4. Adult of Tuta absoluta 


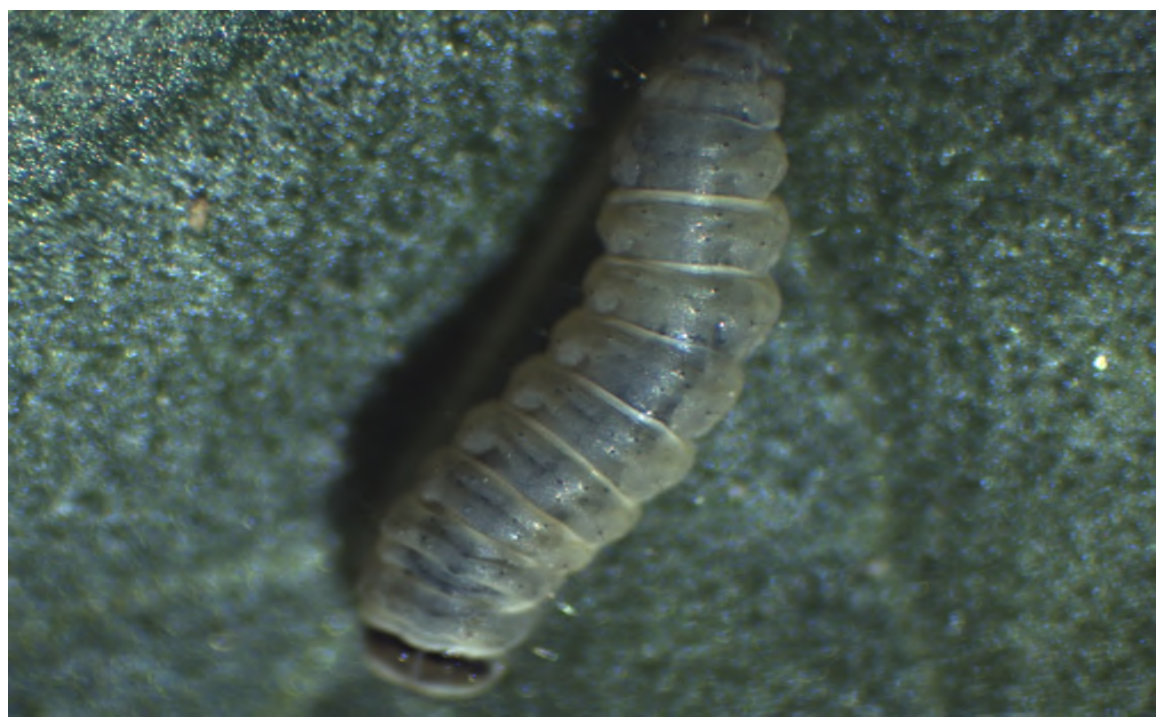

Fig. 5. Larva ( $3^{\text {rd }}$ Instar) of Tuta absoluta

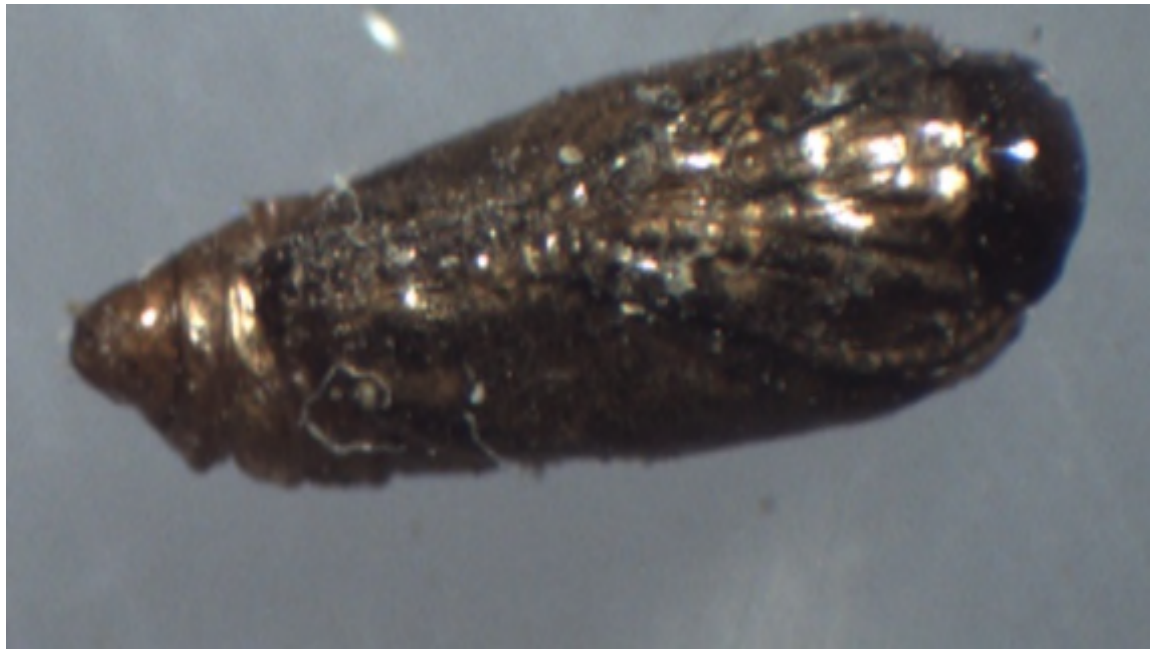

Fig. 6. Pupa of Tuta absoluta

\section{DISCUSSION}

Increase in the geographic area of T. absoluta is a threat for the natural and man-made agricultural ecosystem especially in the regions of south Asia (Desneux et al. 2011). However, in Pakistan T. absoluta has been reported for the first time. The same insect pest has been identified in neighboring country India. Tomato seed and fruits are being imported from India. Most probably it entered Pakistan from India through trade.

Since 1960s T. absoluta got the status of key pest of tomato in South American countries and listed in A2 quarantine list of EPPO (European and Mediterranean Plant Protection Organization) in 2009. In 2006, after its first record in Spain it spread to Europe and North Africa and also sub Saharan African countries in recent years and South Asian countries including Nepal (Bajracharya et al. 2016) and Bangladesh (Hossain et al. 2016). A recent report from Kyrgyzstan (Uulu et al. 2017) confirmed its presence in Central Asia. Now, this insect pest outbreak has spread in all over the tomato cultivating areas of the world.

T. absoluta considered as notorious insect pest of tomato crop for the region. It could be a potential threat to our food security as documented in other countries as it prefers tomato crop than the solanaceous crops (Karadjova et al. 2013; Tumuhaise et al. 2016). It is increasing in the region, there is in dire need to move towards its effective management on solanaceous crops like eggplant, potato, pepper and tobacco as well (Karadjova et al. 2013; Tumuhaise et al. 2016). Monitoring of the pest through crops survey at regular basis and creating awareness among the farmers is very necessary. A collective collaboration in this regard is also a necessary tool with the various organizations such as stakeholders, researchers and extension officers. 
The rapid invasion of $T$. absoluta throughout Afro Eurasia seems to be miscalculated. Its dispersion and invasion among Asian countries got success due to inadequate quarantine measures and absence of combined efforts for surveillance and management. The economic importance of the pest is still unknown to some countries as the pest is not included in quarantine list so far. To manage the pest, more research work is needed to test the validation of existing control measures and successful ones demonstrated by extension workers. Besides these, workshops are recommended to be arranged regularly on ecology and management of $T$. absoluta to promote the collaboration among the partners and stakeholders. $T$. absoluta is a devastating pest, spread rapidly and have potential to ruin the tomato industry, a horticulture based growing enterprise of the country. Keeping in view these facts, regular survey in tomato growing areas, monitoring through sex pheromone traps, active participation of quarantine departments is needed to make pro-active management strategies to overcome the spread of this invasive pest.

Conclusion: This is a first ever documented report of $T$. absoluta from Pakistan. It had never been reported before although it had been warned many times from different scientists for its possible entry points due to increasing trade. It is recommended to take immediate actions to adopt management practices of $T$. absoluta to protect tomato crop in Pakistan.

Acknowledgements: Authors are very thankful to HEC for providing funding to Mr. Sadique under Indigenous PhD Fellowship Program Phase-II and Denis J. Wright Prof. of Pest Management, Imperial College London, for reviewing early version of the manuscript.

Conflict of interest statement: The authors declare that they have no conflict of interest. We will be responsible for any kind of conflict.

\section{REFERENCES}

Anonymous. (2013). Tuta absoluta - Meeting the challenge of the tomato leafminer November 26-28, 2013; Intercontinental Hotel, Addis Ababa, Ethiopia.

Bahamondes, L.A., and A.R. Mallea (1969). Biology in Mendoza of Scrobipalpula absoluta (Meyrick) Povolny (Lepidoptera: Gelechiidae), a new species for the Argentine Republic. Rev. Fac. Cs. Agrarias, UNC (Argentina) 15: 96-104.

Bajracharya, A.S.R., R.P. Mainali, B. Bhat, S. Bista, P.R. Shashank, and N.M. Meshram (2016). The first record of South American tomato leaf miner, Tuta absoluta (Meyrick 1917) (Lepidoptera: Gelechiidae) in Nepal. J. Entomol. Zool. Stud. 4(4): 1359-1363.
Baniameri, V. and A. Cheraghian (2012). The first report and control strategies of Tuta absoluta in Iran. EPPO Bulletin, 42(2): 322-324.

Brevault, T., S. Sylla, M. Diatte, G. Bernadas. and K. Diarra (2014). Tuta absoluta Meyrick (Lepidoptera: Gelechiidae): a new threat to tomato production in Sub-Saharan Africa. Afr. Entomol. 22(2): 441-444.

Cheraghian, A. and P.J. Emamzadeh (2013). First report of the tomato leaf miner, Tuta absoluta (Lep.: Gelechiidae), from Iran. J. Entomol. Soc. Iran 33(3): 87-88.

Desneux, N., M.G. Luna, T. Guillemaud and A. Urbaneja (2011). The invasive South American tomato pinworm, Tuta absoluta, continues to spread in Afro-Eurasia and beyond: the new threat to tomato world production. J. Pest Sci. 84(4): 403408.

Desneux, N., E. Wajnberg, K.A. Wyckhuys, G. Burgio, S. Arpaia, C.A. Narváez-Vasquez and J. Pizzol (2010). Biological invasion of European tomato crops by Tuta absoluta: ecology, geographic expansion and prospects for biological control. J. Pest Sci. 83(3), 197-215.

Duric, Z., S. Hrnčić, M. Vujanović, B. Durić, and S. Mitrić (2012). Tuta absoluta (Meyrick) (Lepidoptera, Gelechiidae) in the Republic of Srpska (Bosnia and Herzegovina). EPPO bulletin 42(2): 337-340.

EPPO. (2018). EPPO Global database (available online). Paris, France: EPPO. https://gd.eppo.int/

Ferracini, C., B.L. Ingegno, P. Navone, E. Ferrari, M. Mosti, L. Tavella and A. Alma (2012). Adaptation of indigenous larval parasitoids to Tuta absoluta (Lepidoptera: Gelechiidae) in Italy. J. Econ. Entomol. 105(4): 1311-1319.

Hayden, J.E., S. Lee, S.C. Passoa, J. Young, J.F. Landry, V. Nazari, R. Mally, L.A. Somma and K.M. Ahlmark (2013). Digital identification of microlepidoptera on solanaceae. Riverdale: USDA-APHIS-PPQ.

Hejazi, M., M.F. Movahedi, O. Askari and B.S. Higbee (2016). Novel chemo-attractants for trapping tomato leafminer moth (Lepidoptera: Gelechiidae). J. Econ. Entomol. 109(5): 20742081.

Hill, M.P., C. Bertelsmeier, S. Clusella-Trullas, J. Garnas, M.P. Robertson and J.S. Terblanche (2016). Predicted decrease in global climate suitability masks regional complexity of invasive fruit fly species response to climate change. Biol. Invasions 18(4): 1105-1119.

Hossain, M.S., M.Y. Mian, and R. Muniappan (2016). First record of Tuta absoluta (Lepidoptera: Gelechiidae) from Bangladesh1. J. Agric. Urban Entomol. 32(1): 101-105. 
Karadjova, O., Z. Ilieva, V. Krumov, E. Petrova and V. Ventsislavov (2013). Tuta absoluta (Meyrick) (Lepidoptera: Gelechiidae): Potential for entry, establishment and spread in Bulgaria. Bulg. J. Agric. Sci. 19(3): 563-571.

Mohamed, E.S.I., M.E. Mohamed and S.A. Gamiel (2012). First record of the tomato leafminer, Tuta absoluta (Meyrick) (Lepidoptera: Gelechiidae) in Sudan. EPPO bulletin, 42(2): 325-327.

Pimentel, D., S. McNair, J. Janecka, J. Wightman, C. Simmonds, C. O'connell and T. Tsomondo (2001). Economic and environmental threats of alien plant, animal, and microbe invasions. Agric. Ecosys. Environ. 84(1): 1-20.

Potting, R.P.J., D.J. Van Der Gaag, A. Loomans, M. Van der Straten, H. Anderson, A. MacLeod and G.V. Cambra (2013). Tuta absoluta, tomato leaf miner moth or South American tomato moth. Ministry of Agriculture, Nature and Food Quality. Plant Protection Service of the Netherlands, Utrecht, The Netherlands.

Ramos, C., F. Officer, O.I.R.S.A. Mexico and T. Figueroa-Cano (2013). Collaborators: Devaiah A. Muruvanda, Senior Risk Manager, USDAAPHIS-PPQ David Holden, Survey Biologist, CFIA Maritza Juárez, Coordinator, Centre-South zone, Epidemiological Surveillance Program, SENASICA.

Roditakis, E., D. Papachristos and N.E. Roditakis (2010). Current status of the tomato leafminer Tuta absoluta in Greece. EPPO bulletin 40(1): 163166.

Shashank, P.R., K. Chandrashekar, N.M. Meshram and K. Sreedevi (2015). Occurrence of Tuta absoluta
(Lepidoptera: Gelechiidae) an invasive pest from India. Ind. J. Entomol. 77(4): 323-329.

Sridhar, V., A.K. Chakravarthy and R. Asokan (2014). New record of the invasive South American tomato leaf miner, Tuta absoluta (Meyrick) (Lepidoptera: Gelechiidae) in India. Pest Manag. Hortic. Ecosys. 20(2): 148-154.

Swathi, P., B. Swathi, S.B. Das, V. Sridhar, O. Giribabu, G. Snehalatha and N. Raypuriya (2017). First report of South American tomato leaf miner, Tuta absoluta (Meyrick) from Madhya Pradesh, India. Pest Manag. Hortic. Ecosys. 23(1): 92-93.

Tumuhaise, V., F.M. Khamis, A. Agona, G. Sseruwu and S.A. Mohamed (2016). First record of Tuta absoluta (Lepidoptera: Gelechiidae) in Uganda. Int. J. Trop. Insect Sci. 36(3): 135-139.

Urbaneja, A., R. Vercher, V. Navarro, M.F. Garcia and J.L. Porcuna (2007). La polilla del tomate, Tuta absoluta. Phytoma Espa na 194, 16 -23. (In Spanish)

Uulu, T.E., M.R. Ulusoy and A.F. Çalışkan (2017). First record of tomato leafminer Tuta absoluta Meyrick (Lepidoptera: Gelechiidae) in Kyrgyzstan. EPPO Bulletin 47(2): 285-287.

Van den Broeck, G. and M. Maertens (2016). Horticultural exports and food security in developing countries. Global food security, 10: 11-20.

Visser, D., V.M. Uys, R.J. Nieuwenhuis and W. Pieterse (2017). First records of the tomato leaf miner Tuta absoluta (Meyrick, 1917) (Lepidoptera: Gelechiidae) in South Africa. BioInvasions Records 6: 301-305. 